\title{
Çözümlenemeyen Bir Halk Sağlığı Sorunu; Acil Servislerin Uygunsuz Kullanımı ve Hastaların Bakış Açıları
}

\section{An Unsolvable Public Health Problem; Improper Use of Emergency Services and Patients' Views}

\author{
Umut Payza $^{1 *}$, Zeynep Karakaya ${ }^{1}$, Fatih Esad Topal ${ }^{1}$ \\ ${ }^{1}$ İzmir Katip Çelebi Üniversitesi Atatürk Eğitim ve Araştırma Hastanesi, Acil tıp ABD, İzmir, Türkiye \\ umutpayza@hotmail.com, zeynepkarakaya76@hotmail.com, fatihetopal_18@hotmail.com \\ Orcid: 0000-0002-5297-1066 \\ Orcid: 0000-0003-0562-8297 \\ Orcid: 0000-0002-9941-4224 \\ *Sorumlu Yazar / Corresponding Author: Sorumlu Yazar: Umut Payza \\ Gönderim Tarihi / Received: 11.07.2019 \\ Kabul Tarihi / Accepted: 05.01.2020 \\ DOI: $10.34087 /$ cbusbed.590562
}

Giriş ve Amaç: Acil servisler Türkiye nüfusunun üzerinde bir başvuru yükü altındadır. Bu sebeple acil servislerde hastalara verilen hizmet kalitesindeki düşüş toplumun ciddi bir kesimini etkileyecektir. Aynı zamanda yüksek başvuru sayıları ciddi bir mali yükü ve hizmet kalitesinde düşüşü de beraberinde getirecektir. Bu ve benzer birçok neden sebebiyle 'Acil servis yoğunluğu' ciddi bir halk sağlığı sorunu haline gelmiştir. Bu çalışmanın amacı acil tıp kliniğine başvuran ve acil müdahale ihtiyacı olmayan hastaların gözünden acil servislere bakış açılarını ve aciliyet algısını değerlendirmektir. Acil servislerin uygun olmayan kullanımı için analitik bir değerlendirme yapmaktır. Gereç ve Yöntemler: 4 ay boyunca İzmir Katip Çelebi Üniversitesi Atatürk Eğitim ve Araştırma Hastanesine başvuran, acil müdahale ihtiyacı olmayan, 919 hasta çalışmaya dahil edilmiştir.

Bulgular: Eğitim durumları incelendiğinde ise, katılımcıların \%14,5'inin herhangi bir eğitim almadıkları görüldü. $\% 7,5$ 'u ilkokul, \%7,9 ortaokul, \%65,8'i lise düzeyinde eğitim almıştır. Başvuranların \%4,3'ü ise üniversite mezunudur. Bununla beraber, acil servisler genç yaş grubu hastalar tarafindan poliklinik yoğunluğu gibi nedenlerle kullanılmaktadır. Aciliyet algısındaki değerlendirme hem hastalarca hem de sağlık çalışanları tarafindan doğru anlaşılamamıştır.

Sonuç: Hastaların aciliyet algısında yanıldıkları ve eğitim düzeyi ne olursa olsun acil servisleri amaçları dışında kullandıklarını gözlemledik.

Anahtar kelimeler: Acil servis yoğunluğu, aciliyet algısı, acil servis kullanım amaçları

\footnotetext{
Abstract

Objective: Emergency services are under a burden application about over numbers of the Turkey's population. For this reason, the decrease in the quality of service provided to patients in emergency services will affect a significant part of the society. At the same time, the high number of applications will entail a significant financial cost. In addition, burnout in employees and violence against health personnel are other important events. For these and similar reasons, 'Emergency department overcrowded' has become a serious public health problem. The aim of this study was to evaluate the perspectives and perceptions of emergency patients. And, to make an analytical assessment for the improper use of emergency services.

Materials and Methods: 919 patients who no need emergency treatment, admitted to Izmir Katip Çelebi University Atatürk Training and Research Hospital for 4 months were included in the study.

Results: When the educational status was examined, we found that $14.5 \%$ of volunteers have no education. And, other parts of volunteers; $7.5 \%$ primary school, $7.9 \%$ secondary school, $65.8 \%$ high school, $4.3 \%$, had university education. However, emergency services are used by young age group patients for reasons such as polyclinic
} 
intensity. Assessment of urgency perception has not been correctly understood by both patients and healthcare professionals.

Conclusion: We observed that patients were wrong in their perception of urgency and that they use emergency services for unnecessary reasons regardless of their educational level.

Key words: Overcrowded of emergency department, perception of patients, purpose of using emergency service

\section{Giriş}

Halk sağlığ1, toplumun bedensel, sosyal ve zihinsel açıdan iyilik halini korumak için çeşitli alanlarda çalışmalar yapar. Bağışıklama, kronik hastalıklar, aile planlaması, doğum kontrolü, sağlık ekonomisi, iş sağlığı, çocuk sağlığı, afetler, salgın hastalıklar, çevre sağlığı... Kısacası; halkın sağlığını ilgilendiren ve toplumda 'herhangi bir nedenle' hastalığa yol açabilecek etkenlerle karşılaşıldığ 1 her durum halk sağlığının konusunu oluşturur. Bu alanlarda toplumun geniş bir parçasını etkileyen olay veya problemlere de 'Halk Sağlığı Sorunu' denilmektedir.

Türkiye, acil servis başvuru sayılarında, özellikle Avrupa ile karşılaştırıldığında ön sıralarda yer almaktadır [1]. Sağlık bakanlığının 2011 yılına ait verilerine bakıldığında her üç kişiden birinin acil servislere başvurduğu görülmektedir. 2015 yılında yaklaşık 15 milyonu çocuk olmak üzere 90 milyonu aşan yıllık acil başvurusu olduğu bildirilmiştir [2]. Bu rakamların sadece acil servis başvuruları olduğu düşünüldüğünde tüm sağlık sisteminin ciddi bir yük altında olduğu görülmektedir. İlerleyen dönemlere bakıldığında hızla artan nüfusun ve coğrafyamızda yaşanan göç dalgalarının da bu yükü arttıracağı açıktır. Başvuruların, yalnızca, sayısal çokluğunu ele alsak dahi, sağlık alt yapımıza ne denli zarar verebileceğini görmekteyiz. Yoğunluk nedeniyle azalmış sağlık hizmet kalitesi, hastalara ayrılan kısıtlı zaman, sağlık çalışanlarının ilgi ve verimliliğinde azalma en sık karşılaşılan sorunlar arasında yer almaktadır. Yüksek sağlık harcamaları mali sorunlara neden olurken yaşanan sağlıkta şiddet olguları da iş sağlığ güvenliği için ciddi bir sorun olarak karşımıza çıkmaktadır.

Hem sağlık hizmetlerinde yaşanan sorunlar hem mali yük hem de çalışan güvenliğine ait sorunlara neden olması nedeniyle acil servis yoğunluğu toplumun tamamını ilgilendiren bir halk sağlığı sorunu oluşturmaktadır. Biz çalışmamızda bu acil servis yoğunluğunun nedenlerini, hastaların bakış açıları üzerinden inceledik. Toplumun gözünde acil servis ve hasta aciliyeti kavramlarını araştırdık. Oluşturduğumuz anketin cevaplarına bakarak ciddi bir halk sağlı̆̆ sorununa 1şık tutmayı amaçladık.

\section{Gereç Yöntem}

Çalışma, araştırma verileri yüz yüze görüşülerek hazırlanmış bir anket çalışmasıdır. Bu anketin soruları acil servis yoğunluğunun temel nedenlerini tespit etmek amacıyla hazırlanmıştır. Anket hekim kontrolünde ve çoktan seçmeli olarak cevaplanacak şekilde uygulanmıştır. Hastaların tedavi/muayene süreçleri tamamlandıktan sonra anket uygulanmıştır. Ankete katılım gönüllülük esasına göre yapılmıştır.

\subsection{Hasta Seçimi;}

Çalışmaya 18 yaş üzeri, acil müdahale ihtiyacı olmayan hastalar alındı. Hastaların hekim tarafindan muayeneleri tamamlandiktan sonra anketi doldurmayı kabul eden hastalar dahil edildi. Alzheimer/demans tanıları olan hastalar çalışmaya alınmadı. Travmaya maruz kalan hastalar çalışma dışı bırakıldı.

\subsection{Veri Toplama}

İzmir Katip Çelebi Üniversitesi Tıp Fakültesi Atatürk Eğitim Araştırma Hastanesi Acil Servisi'nde 01 Haziran 2014 - 31 Eylül 2014 tarihleri arasında müracaat eden, ankete katılmaya gönüllü olmuş, 919 hasta ile yapılmıştır. Acil servis kullanım alışkanlıklarının daha iyi analiz edilebilmesi için 24 saatlik çalışma süresi 8 'er saatlik 3 periyoda ayrıldı. Her 3 periyotta eşit sayıda alınd1.

\section{3 İstatitiksel Analiz}

$\mathrm{Bu}$ çalışma tanımlayıcı nitelikte gözlemsel bir araştırmadır. Çalışma verileri değerlendirilirken tanımlayıcı istatistiksel metotlar (Frekans, Yüzde, Ortalama, Standart sapma) kullanılmıştır. Niceliksel verilerin karşılaştırılmasında $\mathrm{t}$ testi, çoklu grupların karşılaştırması için de Anova testi ve Tukey testi kullanılmıştır. Veriler arasındaki ilişkileri saptamak içinse Pearson Korelasyon analizi kullanılmıştır. Sonuçlar \%95'lik güven aralığında, anlamlılık $\mathrm{p}<0,05$ düzeyinde değerlendirilmiştir.

\section{Bulgular}

Anketimize katılan katılımcı sayısı 919 kişi olup bu katılımcıların \%48,4'ünü (n:445) kadınlar ve \%51,6'ini (n:474) erkekler oluşturmaktadır. Cinsiyetlere göre acil servis başvurularında istatistiksel fark gözlenmedi. Ankete katılan erkeklerin yaş ortalaması 45,4 ve kadınların yaş ortalaması 38.1 idi.

Eğitim durumları incelendiğinde ise, katılımcıların $\% 14,5$ 'inin herhangi bir eğitim almadıkları görüldü. $\% 7,5$ 'u ilkokul, \%7,9 ortaokul, \%65,8'i lise, \%4,3'si üniversite düzeyinde eğitim almıştı. Acil servisin uygunsuz kullanımı ile eğitim düzeyi arasındaki ilişki incelendiğinde lise ve üniversite düzeyinde eğitim alanların acil servisleri amaca uygun kullanmadıkları görüldü (Tablo 1). 
Tablo 1. Eğitim Durumlarına Göre Acil Servis Kullanımı

\begin{tabular}{|c|c|c|}
\hline Eğitim Durumu & N (kişi) & \% \\
\hline Yok & 133 & 14,5 \\
\hline İlkokul & 69 & 7,5 \\
\hline Ortaokul & 73 & 7,9 \\
\hline Lise & 605 & 65,8 \\
\hline Üniversite & 39 & 4,3 \\
\hline
\end{tabular}

Katılımcıların sosyo-ekonomik özelliklerine göre çalışan, çalışmayan ve öğrenci olarak üç grupta sınıflandırıldı. Grubun \%48,3'ü çalışanlar, \%47,8'i çalışmayan \%3,8'ini öğrenciler oluşturdu.

Hastaların analizinin daha açık yapılabilmesi için çalışmanın yaş grupları 18-25 yaş arası bireyler 'genç', 25-40 yaş 'genç erişkin', 40-65 yaş bireyler 'erişkin' ve 65 yaş üstü katılımcılar 'yaşlı' olarak sınıflandırılarak dağılımı incelendi. $\mathrm{Bu}$ dağılıma göre katılımcıların $\% 13,4$ '̈̈ genç $(\mathrm{n}=123), \% 44,5$ genç erişkin (n:409), \%26's1 erişkin (n:239) ve \%16,1'i (n:148) yaşlı bireyler oluşturmaktadır.

Hastalara ankette yer alan sorular soruldu. 'Sizce hastalığınız acil mi?' sorusunu sorarak hastaların kendi aciliyetlerine bakış açıları değerlendirildi. $\mathrm{Bu}$ soruya hastaların \%38,2'si (n;352) evet, \%32,4'ü (n;297) hayır olarak cevap verdi. Hastaların \%29,4’ü $(\mathrm{n} ; 270)$ hekimin hastalık halini değerlendirerek karar vermesi gerekliliğini seçti.

Acil servilere başvuruları öncesi durumlarının acil müdahale gerektirdiği konusunda nasıl bilgi edindikleri soruldu. Hastaların \%28,4'ünün acilimize uğramadan önce başka bir sağlık kuruluşunun acil servisinden hastanemize yönlendirildiği görüldü. Hastaların \%17'si aile hekimleri tarafından, \%31,6'ü diğer branş polikliniklerinden acil servisimize geldiklerini söylediler. \%7'si medyadaki bilgilendirmeler sonrasında acil servislere başvurduklarını, \%15,6'sı herhangi bir bilgilendirme almadan acile geldiklerini belirttiler (Tablo 2). Eğitim düzeyi en az lise ve üzerinde olan hastaların başka kurumlarda değerlendirme ve/veya tedavi uygulansa bile yeniden acil servislere başvurdukları görüldü. Eğitim düzeyi ile aciliyet algısı arasında negatif yönde anlamlı ilişki görüldü.

Tablo 2. Acil Servislere Başvuru Şekillerine Göre Dağılımı

\begin{tabular}{|l|c|c|}
\hline Başvuru & N (kişi) & \% \\
\hline Branş Poliklinleri & 291 & 31,6 \\
\hline Diğer Acil Servisler & 260 & 28,4 \\
\hline Aile Hekimliklerine & 156 & 17 \\
\hline Doğrudan Başvuru & 144 & 15,6 \\
\hline Medya & 68 & 7,4 \\
\hline
\end{tabular}

Hastalarımıza acil servisi tercih etme nedenlerini, çoktan seçmeli ve açık uçlu olacak şekilde, sorduk. Hastaların \%46,7'si acil servis hizmetlerinin kaliteli olduğunu düşündükleri için başvurduklarını ifade etti. \%25'i hızlı olduğunu için ve \%20'si ucuz olduğu için acil servisleri tercih ettiklerini söylediler.

Hastalara 'Acil servisi nasıl tanımlarsınız?' diye sorduk. Hastaların \%40,1'i (n;368) acil servisi tetkiklerin hızlı yapıldığ 1 yer olarak, \%24,3 (n; 223) 24 saat her türlü hizmetin verildiği yer ve \%18,2'si (n; 167) acil hastaların bakıldığı yer olarak tanımladılar. Ankete katılanların \%17,4'ü $\quad(n ; 160) \quad$ diğer sağl1k basamaklarından bir farkı olmadığını düşündüklerini dile getirdiler.

Mesai dışı acil servislerin kullanım nedenlerini de inceledik. Hastaların \%29,4'ü (n;270) çalıştıklarını ve/veya refakatçilerinin çalıştığını bu nedenle mesai saatleri dışında başvuruda bulunduklarını ifade etti.
\%27,5' ü (n; 251) polikliniklerin çok yoğun olduğu için, $\% 11,6$ 'i (n;106)ise ücretsiz hizmet verildiği için acil servise geldiklerini ifade etti. Hastaların \%11'i (n;101) merkezi başvuru sisteminden (MHRS) sira bulamadıkları için acil servise geldiklerini belirtmiştir. \%4,7'si $(\mathrm{n}, 42)$ ise acil servis hizmetlerinin kaliteli olması sebebiyle tercih ettiklerini beyan etmiş̧lerdir. Hastaların \%15,8'i $(\mathrm{n} ; 145)$ rahatsızlıklarının başladığı zaman nedeniyle gelmek zorunda olduklarını söylemişlerdir.

Bir alt grup analizi olarak polikliniklerin yoğun olması nedeniyle acil servise başvurmayı tercih eden hastaların yaş dağılımlarına baktığımızda; \%12,7'sinin 18-25 yaş, \%48'inin 25-40 yaş, \%23'ünü 40-65 yaş bireylerin oluşturduğu görüldü. 65 yaş üzeri başvuru oranı $\% 16,3$ idi. Poliklinik kalabalığı nedeniyle acil servisleri tercih etme ile yaş arasında negatif yönlü kuvvetli bir ilişki görüldü. 
Hastalarımıza acil servisin yoğunluğundan rahatsız olup olmadıklarını da sorduk. Hastalarımızın \%47,7'si oluşan yoğunluktan rahatsız olduklarını söylerken, \%52,3'ü yoğunluktan rahatsız olmadıklarını ifade etti.

\section{Tartışma}

Acil servisler sağlik sistemin en önemli basamaklarından birini oluşturmaktadır. Acil servislerin daha verimli çalışabilmesi, servis ve hastane olanaklarının yeterli düzeyde kullanılabilmesi, toplum sağlığı açısından da oldukça önemlidir. Ancak, özellikle ülkemizde, acil sağlık hizmetleri ve acil servisler maksadının dışında ve kapasitelerinin üzerinde hizmet vermek zorunda kalmaktadır. $\mathrm{Bu}$ durum özellikle hizmet kalitesini düşürmekte ve hayatı tehdit edici durumlarla mücadelede ciddi zafiyete neden olmaktır [3].

Avrupa ve OECD ülkeleri ile karşılaştırıldığında, acil servis başvuruları nüfusa göre en fazla olan ülkenin Türkiye olduğu saptanmıştır [1]. 2018 yilında 110 milyon acil servis başvurusu yapılmıştır [2].

Acil servislere yapılan başvuruların uygunsuzluğu, sağlık ekibinde zaman kaybı, iş yükünde artış ve dikkat azalmasına yol açmakta ve gerçek acillere gerekli zaman ve dikkat verilmesine bir engel oluşturmaktadır [4]. Bununla beraber çalışanlarda tükenmişlik düzeyini arttırmakta hem psikolojik hem fiziksel yıpranmalara neden olmaktadır [5]. Meydana gelen yoğunluk hasta/hasta yakını ile hekimler arasında şiddet olaylarının artışını da tetiklemektedir [6]. Ayrıca acil servislerin uygun olmayan kullanımı sağlık giderlerinde ciddi bir artışa neden olmaktadır ve bu yük toplumun tamamını etkilemektedir [7]. Bu gibi nedenlerle acil servis yoğunluğu ve uygunsuz kullanımını etkileyen faktörleri belirlemek toplum sağlı̆̆ için verilen hizmet kalitesini arttıracak ve ekonomik olarak sağlık sistemini rahatlatacaktır.

Biz çalışmamızda toplumun bakış açısını değerlendirerek acil servis yoğunluğunun sebeplerini belirlemek için bir anket çalışması uyguladık. Acil müdahale ihtiyacı olmadığı hekimler tarafından belirlenen 'yeşil kod' hastalara çoktan seçmeli ve açık uçlu sorular sorduk. Acil servisi kullanan ve acil müdahale gereği olmayan bu hastaların acil servisleri nasıl ve ne amaçla kullandıklarını inceledik.

Anketimize katılımcıların demografik özelliklerine inceledik. Bizim çalışmamızda hastaların \%48,4'ü (n:445) kadın, \%51,6's1 (n:474) erkekti. Edirne ve ark., yaptıkları çalışmada başvuruların \%43,2'si erkek, $\% 56,8$ ' $\mathrm{i}$ ise kadındı [8]. Köse ve ark çalışmalarında ise erkeklerin $(\% 54,8)$ oranın kadınlardan $(\% 45,2)$ fazla olduğu görülmüştür. Erkek ve kadınların başvuruları arasında istatistiki anlamlılık bulunmamakla beraber Bunun nedeni erkeklerin refakat ihtiyacı olmadan daha kolaylıkla acil servisimize başvurması olabileceğini düşünüyoruz.

Ersel ve arkadaşlarının yaptıkları çalışmada başvuran hastaların \%43,4'si 17-39 yaş arasında, \%39'u 40-64 yaş arasında, \%17,6'si ise 65 yaş ve üzerinde olduğu görüldü [9]. Bizim çalışmamızda da yaş gruplarının dağılımına bakıldığında; hastaların \%13,4’ü 18-25 yaş, \%44,5'i 25-40 yaş, \%26's1 40-65 yaş ve \%16,1'i 65 yaş üstü idi. Acil servise başvuran hastalarımızın çoğunluğu, 'Dünya Sağllk Örgütü'nün belirlediği yaş dilimlerine göre, genç hasta grubundan oluşmaktadır [10]. Acil servislerin kullanım yoğunluğunu oluşturan yaş grubu tahmin edilenin aksine genç bireylerden oluşmaktadır ve sonuçlarımız ülkemizde yapılan diğer çalışmalarla uyumludur.

Çalışmamızda aciliyet algılarını değerlendirmek için hastalara 'Sizce hastalığınız acil mi?' diye sorduk. Hastalarımızın \%38,2'si (n;352) evet, \%32,4'ü (n;297) hayır, \%29,4'ü (n;270) aciliyet durumuna hekimin karar vermesi gerektiğini ifade etmişti. Makalemizin verilerine bakıldığ 1 zaman bireylerin sağlık hizmetini kullanımını etkileyen birçok neden mevcut olduğunu görmekteyiz. Sağlık hizmetini kullanım sıklığı ve hizmet türü kişilerin ihtiyaçlarına göre değişmektedir. İhtiyacı şekillendiren faktörlerden birisi de bireylerin hastalıklarına dair algı olduğu belirtilmiştir [11]. Afilalo ve ark., tarafından yapılan çalışmada da sağlık hizmetlerinin uygunsuz kullanımının asıl nedeni olarak hastaların aciliyet algısındaki yanılgılar ve kavramın bir standartı olmaması olduğu vurgulanmıştır [12]. Bizim çalışmamızda da hastaların aciliyet algılarını yanlış değerlendirdiklerini gördük. Bununla beraber yaş grubunun genç ve orta yaşlı bireylerden oluşması dikkat çekicidir. Sağlık kuruluşlarında değerlendirilmelerine rağmen tekrar başvurmaların olması da dikkat çeken başka bir noktadır. Eğitim düzeyinin yükselmesine rağmen aciliyet algısının negatif yönde etkilendiği de görülmektedir. Aciliyet kavramının ve acil servislerin kullanım özelliklerinin topluma yeterli olarak anlatılamadığı anlaşılmaktadır. Eğitim düzeyi ne olursa olsun bireylerin aciliyet algısında düzelme görülmemesi toplumsal bilinçlendirmenin eğitimin her safhasında aksadığı veya yetersiz kaldığını göstermektedir. Uludağ Üniversitesi'ndeki çalışmada başvuran hastaların \%62,3'ünün acil olmayan başvurular olduğu görülmüş ve makalemizde ortaya konan eksiklikler benzer şekilde tespit edilmiştir [13].

Tayfun Aydın ve ark yaptığı çalışmada evden doğrudan başvuru \%70'tir [13]. Bizim çalışmamız da ise acil servilere başvuruları öncesi herhangi bir sağlık kuruluşuna başvurular sorgulandığında hastaların önemli bir kısmını diğer sağlık birimlerinden geldiği görülmektedir. Evden başvuru oranı düşüktür. Acil servisimizin iş yükündeki artışın temel nedeni diğer sağlık kuruluşlarından farklı nedenlerle acil servisimize gelen hastalardır. Burada yalnızca hastaların değil hastaları yönlendiren sağlık çalışanlarının da aciliyet algılarını değerlendirmek gereklidir. Herhangi bir acil müdahale ihtiyacı olmayan hastaların toplum sağlığ merkezleri, aile hekimlikleri, poliklinikler gibi sağlık basamaklarının başka hastane ve acil servislere yönlendirilmesi hekimlerin de aciliyet algısında yanıldıklarını düşündürmektedir.

Acil servisi nasıl tanımlarsınız? Acil Tıp, kişilerin sağlık sorunlarında ölümlerin ve kalıcı sakatlıklarının önlenmesinde gerekli olan hızlı müdahale ve hızlı karar vermeyi içeren bir bilimdir. Acil servisler tüm dünyada 
daha etkin ve hızlı müdahale olanakları sağlamak için gelişen ve sağlık sistemlerinin temelini oluşturan hizmet birimleridir. Ancak, özellikle ülkemiz gibi gelişmekte olan ülkelerde, acil servisler amaç ve kapsamları dışında hizmet vermek zorunda kalmaktadır. Acil servisi kullanan hastaların gözünden bakıldığında başka bir gerçekle karşılamaktayız. Hastaların yalnızca \%18'i acil servislerin kullanım amacına uygun bir tanımlamayı yapmışlardır. Ülkemizde yapılan çalışmalarda benzer sonuçlar içermektedir. Erenler ve ark., yaptıkları çalışmada acil servislere hayati müdahale için gelen hastaların yıllık ortalama \%3 kadar olduğunu belirtmişlerdir [14]. Tayfun Aydın ve arkadaşlarının yaptıkları çalışmada da acil servislerde muayene olan hastaların \%62,3'ünün acil müdahale gereği olmadığı belirtilmiştir [13]. $\mathrm{Bu}$ açıdan bakıldığında acil servislerin kullanım koşul ve özelliklerinin toplumun tamamına doğru anlatılamadığı fikri öne çıkmaktadır.

Acil servis yoğunluğunun mesai saatleri dışında artış nedenlerini incelediğimizde, hastaların üçte birinin kendileri/refakatçilerinin çalışma saatleri nedeniyle acil servisi mesai dışı periyotta kullandıklarını, üçte birinin ise polikliniklerin çok yoğun olması nedeniyle sadece zaman kazanmak/beklememek için acil servisleri kullandıkları görülmektedir. Katkı payı ödememek, randevu alamamak gibi nedenlerinde azımsanmayacak oranda olduğu çalışmamızın bir diğer sonucudur. Buna paralel olarak polikliniklerin yoğun olması nedeniyle acil servise başvurmayı tercih eden hastaların yaş dağılımlarına baktığımızda daha çok genç yaştaki hastaların bekleme süreleri nedeniyle acile geldiği görülmektedir. Dünya Sağlık Örgütü'nün yaş dilimlerine bakıldığında hastaların yalnızca beşte biri yaşlıdır. Poliklinik yoğunluğundan şikayetçi olanların yaş ortalamasının tahmin edilenin aksine genç olması tıbbi ihtiyaç nedeninden daha çok acil servislerin 'kısa yol' olarak görülmesi gerçeğini ortaya koymaktadır. Hem tıbbi yardıma ihtiyacı olan hastaların zamanından kayıplara hem de acil servis yoğunluğu nedeniyle daha düşük hizmet kalitesinin oluşmasına neden olunmaktadır. Murat Ersel ve ark., yaptıkları Bir başka çalışmada ise acil servisin en çok tercih sebebi güvenilir bulunması olarak ortaya konulmuștur [9].

Acil servislerin yoğunluğu ve uygunsuz kullanımı için oldukça fazla yayın vardır. Günümüzde Amerika'da bile yoğunluk sorunu eyaletlerde yaygındır ve kriz hali olarak gündeme alınmaktadır. Bugüne kadar çözüme yönelik somut çözümlere ise ulaşılamamıştır. Ancak bu sorun yalnız acil servisleri kullanan hastalar ve/veya çalışanlar için bir sorunmuş gibi görülmemelidir. Toplumun her bireyini hem sağlık alt yapısında oluşan sorunlar hem de ekonomik nedenlerle tehdit etmektedir. $\mathrm{Bu}$ nedenle acil servis yoğunluğu ulusal bir sorun olarak algılanmalı ve çözüm için girişimlere hızla başlanmalıdır.

\section{Sonuç}

Türkiye'de acil servis kullanımındaki sorunların saptanması ve çözümü gerçek verilerle yapılacak analitik çalışmalar arttırılmalıdır. Özellikle göç ile beraber yaşanan kültürel değişim de dikkate alınarak acil servislerin uygunsuz kullanımı için eş zamanlı sosyal-sağlık politikalarında köklü yapısal değişikliklerin hızlı bir şekilde hayata geçirilmesi gerekmektedir.

\section{Referanslar}

1.Emergency Care Services: Trends, Drivers And Interventions To Manage The Demand; Health Working Papers Oecd Working Paper No. 83. Delsa/Hea/Wd/Hwp(2015). Http://Www.Oecd.Org/HealthSystems/Health-Working-Papers.Htm01-Sep-2015 (Accessed 11.05.2018)

2. Kamu hastaneleri genel müdürlüğü, Genel sağlık istatistikleri; acil servis istatistikleri; 2016 yllı verileri

http://www.rapor.saglik.gov.tr/istatistik/rapor (accessed 16.06.2018).

3. Trzeciak, S, Rivers, EP, Emergency department overcrowding in the United States: an emerging threat to patient safety and public health, Emergency Medical Journal, 2003,20 (5), 402-5.

4. I-Min, Chiu, Yan-Ren, Lin, Yuan-Jhen, Syue, Chia-TeKung, KuanHan, Wu, Chao-Jui, $\mathrm{Li}$, The influence of crowding on clinical practice in the emergency department, The American Journal of Emergency Medicine, 2018, 36(1), 56-60. https://doi.org/10.1016/j.ajem.2017.07.011.

5. Moukarzel, A, Michelet, P, Durand, A, Sebbane, M, Bourgeois, S, Markarian, T, at al, Burnout Syndrome among Emergency Department Staff: Prevalence and Associated Factors BioMed Research International, 2019 Article ID:6462472, https://doi.org/10.1155/2019/6462472.

6. Rasha, F, Abdellah, L, Khaled, M, et al, Prevalence and risk factors of workplace violence against health care workers in emergency department in Ismailia, Egypt. Pan African Medical Journal, 2017, 26, 21, doi:10.11604/pamj.2017.26.21.10837.

7. Natasha, J, Clifford, S, Fox, AR, O'Connell, J, Gardner, G, The impact of nurse practitioner services on cost, quality of care, satisfaction and waiting times in the emergency department: A systematic review, International Journal of Nursing Studies, 2015, 52(1), 421-435, https://doi.org/10.1016/j.ijnurstu.2014.07.006.

8. Edirne, T, Edirne, Y, Atmaca, B, Keskin, S. Yüzüncü Yıl Üniversitesi Tıp Fakültesi Acil Servis Hastalarının Özellikleri. Van Tip Dergisi, 15 (4), 107-111, 2008.

9. Ersel, M, Karcioğlu, Ö, Yanturalı, S, Yürüktümen, A, Sever, M, Tunç, MA, Bir Acil Servisin Kullanım Özellikleri ve Başvuran Hastaların Aciliyetinin Hekim ve Hasta Açısından Değerlendirilmesi, Turkish Journal of Emergency Medicine, 2006, 6(1), 025-035.

10. Duyar İ. Eds: Mas, R, Ișık, AT, Karan, MA, Beğer, T, Akman, S, Ünal, T. In: Geriatri, Bölüm 1: Gerontolojinin Temelleri. Ankara: TGV; 2008: 9-19.

11. Erdem, R, Prinçci, E, (2003), "Sağlık Hizmetlerinde Kullanım ve Kullanımı Etkileyen Faktörler”, O. M. Ü. Tip Dergisi, 20(1): 39-46.

12. Afilalo, M, Guttman, A, Colacone, A, et al. Emergency Department Use and Misuse. Journal of Emergency Medicine, 1995;13(2):259264.

13. Aydın, T, Akköse Aydın, \$̧, Köksal, Ö, Özdemir, F, Kulaç, S, Mehtap B, Uludag Üniversitesi Tip Fakültesi Hastanesi Acil Servisine Başvuran Hastaların Özelliklerinin ve Acil Servis Çalıșmalarııı Değerlendirilmesi. JAEM, 2010, 163-8. doi:10.5152/jaem.2010.006

14. Erenler, AK, Akbulut, S, Guzel, M, Cetinkaya, H, Karaca, A, Turkoz, B, Baydin, A. Reasons for Overcrowding in the Emergency Department: Experiences and Suggestions of an Education and Research Hospital. Turkish Journal of Emergency Medicine, 2016, 26, 14(2), 59-63, doi: 10.5505/1304.7361.2014.48802 
http://edergi.cbu.edu.tr/ojs/index.php/cbusbed isimli yazarın CBU-SBED başlıklı eseri bu Creative Commons Alıntı-Gayriticari4.0 Uluslararası Lisansı ile lisanslanmıştır.

(c) $(1)(9)$ 